\title{
Analysis of Power Transformer Insulation: A Case Study in 150 kV Bantul Substation
}

\author{
Arief Rahman Hidayat ${ }^{1}$, Agus Jamal ${ }^{* 1}$, Anna Nur Nazilah Chamim ${ }^{1}$, Ramadoni Syahputra ${ }^{1}$, \\ Jeckson $^{2}$ \\ ${ }^{1}$ Department of Electrical Engineering, Universitas Muhammadiyah Yogyakarta \\ J1. Lingkar Selatan, Tamantirto, Kasihan, Yogyakarta, Indonesia \\ ${ }^{2}$ Department of Electrical Engineering, Universitas Muhammadiyah Lampung \\ J1. Zainal Abidin Pagar Alam 14. Lahuban Ratu, Bandar Lampung, Indonesia
}

*Corresponding author, e-mail: agus_jamal@umy.ac.id

\begin{abstract}
Insulation of the transformer is one of the essential components. So that the quality of the resistance in the isolation of the transformer is essential to note the condition, in order to find out the condition of the transformer isolation, several tests must be performed, namely the polarization index, delta tangent, and break down voltage. In this study, all three tests were carried out on Transformer 1 in the $150 \mathrm{kV}$ Bantul substation. Polarization index testing itself is testing the leakage current on the transformer isolation by comparing the test results for 1 minute with the results of the 10-minute drive test. While delta tangent is testing capacitive leakage current in the isolation transformer, and break down voltage is a test of the ability of the breakdown voltage in transformer insulation oil. Based on the results of the analysis, it can be seen that the value of the transformer polarization index in 2016 and 2018, the average value between the windings has been in the rating of 1.25-2.0. As for the delta tangent test results in 2016 and 2018, the value between the capacitive parts is already in the rating of $0.18 \%-0.36 \%$. For the breakdown voltage test results in 2016 and 2018, the average breakdown voltage value is $43.9 \mathrm{kV} / \mathrm{mm}-65.5 \mathrm{kV} / \mathrm{mm}$. From these data, it can be concluded that the transformer isolation conditions in 2016 and 2018 are in good condition, although there was a decline in the transformer isolation conditions in 2016. However, the National Electric Company has made repairs and maintenance of the isolation transformer. This is seen due to an increase in the quality of transformer insulation in 2018. Repair and maintenance of transformer insulation are done to maximize the work system and the life of the transformer.
\end{abstract}

Keywords: Power Transformer, Insulation, Polarization Index, Delta Tangent, Breakdown Voltage

\section{Introduction}

Nowadays, electrical energy is one of the basic needs of human life. Almost all humans need electricity every day. The longer the electricity demand in Indonesia is increasing and not only for personal needs but also for general needs that are increasing along with the advancement of infrastructure in various regions. To meet the many electrical energy needs, a reliable electricity system is needed, such as a power transformer in the substation [1]-[2].

The power transformer is the leading equipment in the electric power system because it is directly related to the electricity transmission and distribution system. Power transformer functions to convert electrical power from high voltage to low voltage or from low voltage to higher voltage [3]. Disturbances that occur in the transformer can result in the loss of electrical power to consumers. Therefore maintenance and testing need to be done regularly so that the transformer can operate according to its maximum usage period [4].

Several essential parts in a power transformer require routine and specialized maintenance. Moreover, a critical part of the power transformer is the isolation system. Isolation on this power transformer serves to separate the two parts of the voltage or can also be called as a safety between the 
coils on the power transformer [5]. Along with the length of time of operation, the condition of the transformer insulation can decrease. A decrease in conditions on this transformer can cause operation failure and damage to the transformer. This can be caused by several factors such as overvoltage, humidity, high operating temperature, leaking lines on external surfaces such as dirt on the insulator, or damage to the mechanical system [6]. To prevent the failure of the transformer during operation, several essential tests are more often carried out to determine the status of the conditions of transformer. So that the operation failure on the transformer can be prevented before damage to the transformer. Because damage to the power transformer can disrupt the distribution of electrical energy to the community.

Preventive maintenance needs to be carried out for maintenance and testing of the power transformer as a precaution against failure of an operation. Preventive maintenance itself is routine maintenance that is carried out based on internal time specified in specific requirements or criteria intended to reduce and prevent equipment from experiencing an undesirable condition. Some of the insulation resistance testing methods performed during power transformer preventive maintenance are testing the polarization index, voltage ratio, delta tangent, and testing the oil condition using a BDV (break down voltage) test [7].

The aim of this research is:

1. To find out how to test insulation resistance on power transformers in the $150 \mathrm{kV}$ substation Bantul.

2. To determine the condition of the insulation resistance of a suitable power transformer and according to standards based on the results of the test of polarization index, voltage ratio, delta tangent, and BDV (Break-down Voltage).

3. To compare the condition of the transformer insulation based on the data of the results of the current insulation resistance test with the data of the results of the previous insulation resistance test.

The benefits of this research are:

1. The readers can know how to test the insulation resistance on a power transformer at the $150 \mathrm{kV}$ substation in Bantul.

2. The readers can determine the condition of the insulation resistance of a suitable power transformer and according to standards based on the results of the polarization index test, voltage ratio, delta tangent, and BDV (Break-down Voltage).

3. The readers can evaluate the results of the comparison of the transformer insulation conditions based on the data of the results of the current insulation resistance testing with the data of the results of the previous insulation resistance testing.

\section{Literature Study}

\section{II.1 Power Transformer}

A transformer is an equipment in an electric power system that can convert an AC mains voltage at a particular voltage level to a higher voltage level or a lower voltage level based on the principle of electromagnetic induction. Transformers in electric power systems are usually used to increase or decrease AC voltage (step up and step down transformers). Besides, the transformer can also be used as voltage sampling, current sampling, and also changing impedance. Moreover, in the transformer, there are two or three turns/coils (winding) that are used to coat the ferromagnetic iron core. Besides functioning as a ferromagnetic iron core wrapper, the coil or coil also functions as a producer of magnetic fields when electrified [8].

A transformer is equipment in an electric power system that is very reliable and can transform voltage with a reasonably long period of maintenance is carried out routinely and well. Because if there is damage to the transformer that is quite serious, the repair will require a long time at a price that is quite expensive. Then the way to overcome them is by ensuring that the transformer is installed correctly and properly maintained. Therefore the transformer must be maintained by using the system and the correct equipment, good and right.

Based on maintenance requirements, the transformer can be divided into three types, namely:

1. Insulation medium.

2. Construction.

3. Application and usage.

Based on the application and its use, transformers can be divided into five types, namely distribution transformers, network transformers, Arc-Furnance transformers, rectifier transformers, and power transformers.

\section{Distribution Transformer}

Distribution transformers are transformers that have a rating of 3-500 kVA. Generally, these transformers are used in $20 \mathrm{kV}$ electricity substations and are found on electricity distribution poles. Distribution transformers have a variety of types that depend on the cooling system, the type of 
insulation, application services, and installation methods. However, almost all distribution transformers use natural cooling systems.

\section{Network Transformer}

A network transformer is a transformer that has characteristics similar to the distribution transformer. However, in its application, the transformer is slightly different. This type of transformer has unique requirements for network services, such as ventilation, vault size, immersion capability, and short circuit requirements. This network transformer can have a rating of more than $500 \mathrm{kVA}$.

\section{Arc-Furnace Transformer}

The arc-furnace transformer is a transformer that has a particular purpose that is used in industrial processes. Because this transformer has a low voltage with a high current and is used correctly to withstand mechanical stress caused by a predetermined current fluctuation. This type of transformer also has additional coil insulation because arcs of fire can distort the waves.

\section{Rectifier Transformer}

Rectifier transformer is a transformer used for rectifier from $\mathrm{AC}$ to $\mathrm{DC}$ in a process in the industry. Moreover, this transformer is specially designed so that it is resistant to mechanical stresses due to high currents.

\section{Power Transformer}

A power transformer is a transformer that has a rating of more than $500 \mathrm{kVA}$ and is mainly used to convert energy from generating stations to transmission lines, from transmission lines to distribution substations, or from utility service lines to distribution substations. Generally, these transformers are placed in $500 \mathrm{kV}, 150 \mathrm{kV}$, and power generation systems. Figure 1 shows the power transformer in a substation.

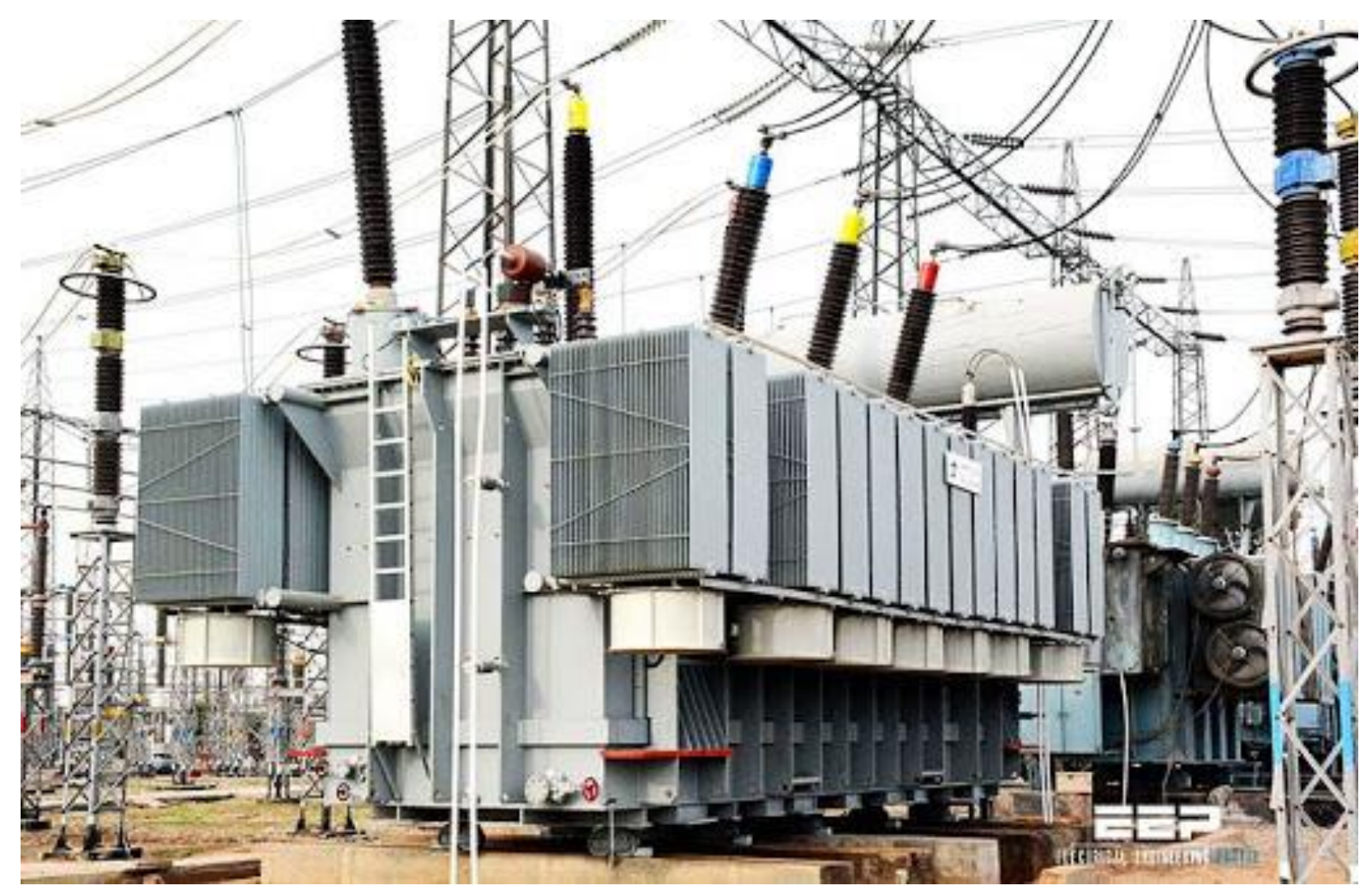

Fig. 1. The power transformer in a substation

\section{II.2 Insulation of Power Transformer}

Based on the insulation medium, the transformer can be divided into two types, namely dry type, and wet type [9].

\section{Dry Type}

The dry-type transformer is a transformer that is free of maintenance because this type of transformer does not use oil or transformer oil as a coolant but uses a fan inside the transformer unit. However, due to the relatively high heat, this type of transformer also requires special treatment by making the room temperature stable so that the dry type transformer requires $\mathrm{AC}$ (Air Conditioning) as additional cooling. The dry-type transformer also has a device used to monitor the condition of the 
transformer and a trip device that will be active if there is overheating or overheating of the transformer itself. In general, this dry type transformer uses two types of cooling, namely natural cooling and artificial cooling. Figure 2 shows the typical of dry type power transformer, while the typical of dry type power transformer was shown in Figure 3.

a. Natural cooling

Natural cooling on the transformer is a cooling system that uses natural circulation from the air through the transformer box.

b. Artificial cooling

Artificial cooling on a transformer is a cooling system that uses air that is forced into the air circulation. Transformers of this type have equipment such as a fan that is used to force air into the transformer. This transformer has a rating of $133 \%$ of the self-cooled dry type transformer rating. The cooling design class for this transformer is FA. A dry-type transformer can be obtained with both self-cooling and forced cooling. The design of the transformer is AA / FA. Dry-type transformers can also be cooled by gases other than air. For such transformers, a sealed tank is needed.

\section{Wet Type}

Wet type transformer is a transformer whose coil and core are completely immersed in the insulating liquid, which is inserted into the transformer tank. This tank is equipped with cooling fins for circulation from the transformer liquid. There are two types of insulating fluids used in transformers, namely mineral oil and polychlorinated biphenyls (PCB) or commonly referred to as askarel. Askarel is a non-flammable synthetic insulation liquid. However, askarel is nonbiodegradable and toxic. The Environmental Protection Agency (EPA) prohibits the use of askarel in transformers, other electrical equipment, and in new applications askarel is almost never used again. Askarel liquid at this time can be replaced with silicon, Rtemp, Wecosal, and Alpha 1.

Based on the cooling method, there are several cooling methods on the wet type transformer that can be used, namely:

\section{a. ONAN (Oil Natural Air Natural)}

ONAN (Oil Natural Air Natural) is a cooling system on a wet type transformer, which is cooling itself using natural circulation from oil. Through the current convection that has been regulated in oil circulated to the tank and cooling fins, the excess heat temperature in the transformer can be removed.

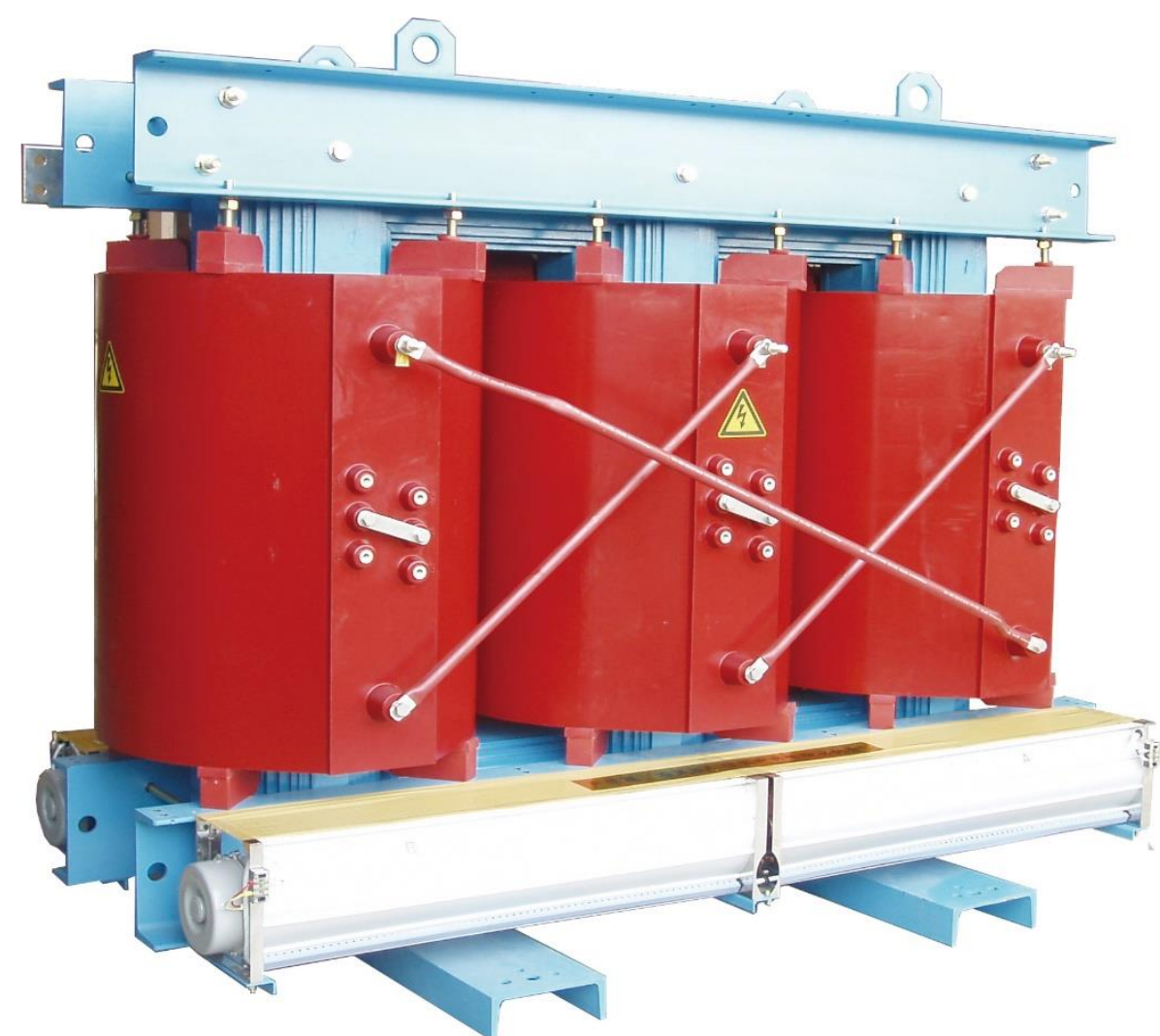

Fig. 2. Typical of dry type power transformer 


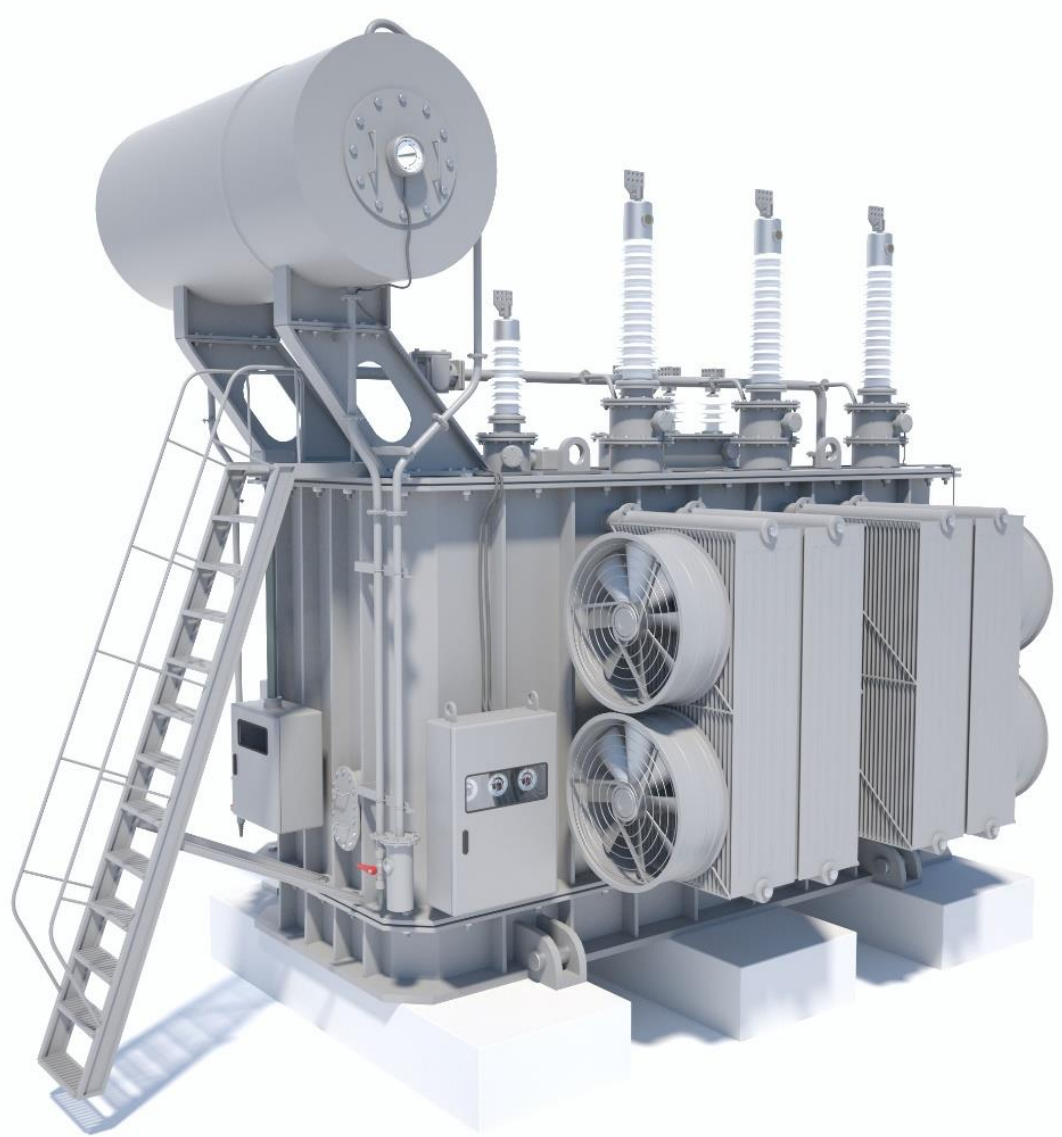

Fig. 3. Typical of wet type power transformer

\section{b. ONAF (Oil Natural Air Forced)}

ONAF (Oil Natural Air Forced) is a cooling system on a wet type transformer that cools itself using oil that will circulate naturally, but when oil through the radiator, the oil will be cooled assisted by a fan.

\section{c. OFAF (Oil Forced Air Forced)}

OFAF (Oil Forced Air Forced) is a cooling system on a wet type transformer that cools itself using oil that has been cooled with a pump so that its circulation becomes faster and with the help of fans on the radiator.

\section{d. Water cooling}

Water cooling is a cooling system on a wet type transformer that uses water to produce cold temperatures. This cooling system is a process of exchanging heat from the water, which is then pumped through pipes that are installed inside or outside the transformer tank.

Especially for this type of wet type transformer, the coil and transformer core will be immersed in the transformer oil. Generally, the transformers have a large enough capacity. The reason is soaked because this transformer oil functions as a cooling medium and also has properties as an insulating material or has a high breakdown voltage value.

Based on the shape of its construction, the transformer can be divided into two types, namely tank construction, and core construction.

1. Tank construction

Tank construction is a type of tank used in transformers and serves to prevent the opening of insulating liquid or oil into the atmosphere. The following are some types of tank construction in transformers.

a. Free-breathing

Free-breathing is a type of transformer tank used for breathing. The function of the breathing transformer is as a change of air pressure and the temperature outside the tank. Moreover, some of these transformers in the breather section can be equipped with a liquid dehydration component.

b. Conservator and expansion tank

Transformers of this type are equipped with conservators and expansion tanks. The conservatory itself is used to seal the transformer liquid from the atmosphere, to reduce oxidation and sludge formation. While the expansion tank serves as an aide to balance the pressure. This expansion tank is usually placed on the 
transformer tank.

c. Sealed tank

Transformers of this type are equipped with inert gases, such as nitrogen, which are on top of the transformer tank. So that this sealed tank functions to seal the inert gas.

d. Gas-oil sealed

The transformer in this type has an additional tank, which is a gas oil-sealed tank. This tank serves to seal the gas and liquid in the transformer, so it does not come out into the atmosphere.

e. Vaporization

Transformers of this type use special nonflammable insulating liquids, such as fluorocarbons (General Electric R-113), and these transformers also have individual condensers welded to the top of the transformer tank. This condenser serves to cool the air vapor and make it a liquid.

2. Core Construction

Based on the core construction, the transformer can be divided into two types, namely the core and shell types.

a. Core type

In this type of transformer, the transformer winding will surround the laminated magnetic core of the transformer. Moreover, most of the small power distribution transformers will use a core construction like this.

\section{b. Shell Type}

The transformer of this type, the magnetic transformer core which will surround the coil (winding). Moreover, another advantage of this shell type is that the transformer offers a separate path for zero sequence current through the core. In contrast, the type of core transformer for the zero-sequence current is only through the transformer tank and the connection end.

\section{Methodology}

The tools and materials used consist of hardware and software, namely:

1. Hardware

Hardware (Hardware) used in writing this research is a unit of Asus A455L laptop and a printer.

\section{Software}

The software used in this research is MS Office 2016 (Microsoft Word 2016 and Microsoft Excel 2016).
This research activity was carried out at PT PLN (Persero) $150 \mathrm{kV}$ substation Bantul located at Jalan Parangtritis km 7, Sewon, Druwo, Bangunharjo, Bantul, Special Region of Yogyakarta, Indonesia, as can be shown in Figure 4.

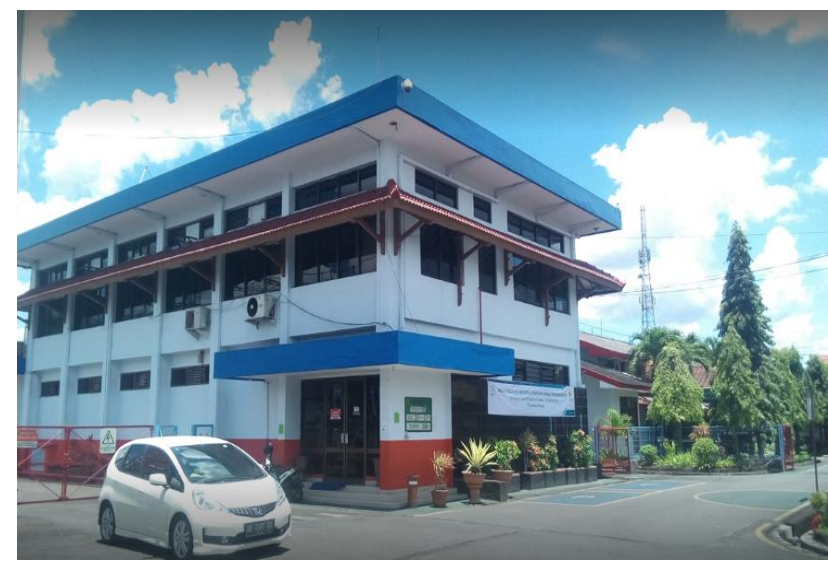

Fig. 4. Location of PT PLN (Persero) $150 \mathrm{kV}$ substation Bantul

To provide a more precise explanation of the steps taken in conducting research below is given a more detailed explanation in full from each of the following studies.

1. Preliminary Study

This stage is the first stage carried out in writing the final project. In this step, a field study was carried out by directly observing the state of the transformer and the polarization index testing instruments, delta tangent, BDV, and conducting interviews with the person in charge at PT. PLN (Persero) $150 \mathrm{kV}$ substation Bantul. Observations and direct interviews are carried out to know the initial information about the conditions in the field.

\section{Problem Identification and Formulation}

The next stage is the stage of identifying the problem. In this stage, the problem of knowing the transformer isolation conditions are examined. Therefore it is necessary to collect various data related to the problem to support research in this research.

\section{Literature Study}

At this stage, the aim is to find information about theories, methods, and concepts related to the issues raised and can be used as a reference in solving the problems of this research. The step of the literature study is to look for information and references in any form, such as journals, textbooks, or other reliable sources.

4. Observation of Polarization, Tangent Delta and BDV Index Test Equipment

At this stage, observations will be made on the 
test equipment and the method of testing the polarization index directly, delta tangent, and BDV at PT. PLN (Persero) $150 \mathrm{kV}$ substation Bantul. Moreover, at this stage will be carried out to determine the parameters needed for research, so that the data collection is carried out to the maximum.

\section{Data Collection, Processing, and Analysis}

This data collection is done by observing directly in the field, conducting interviews with relevant technicians, as well as existing supervisors. The parameters taken are the polarization index test data, delta tangent, BDV, and so on.

Some parameters included in the analysis are power loss, applied voltage, and capacitance values. From the above parameters are parameters in determining the delta tangent value.

6. Results and Conclusions

After data processing and analysis are done well, conclusions can be drawn from the research conducted.

\section{Results and Discussion}

\section{IV.1 Insulation of Power Transformer}

The transformer is equipment in an electric power system that functions as a modifier of the voltage value, which is very important for the process of distributing electrical energy. The condition of the transformer must always be maintained so that damage does not occur that could inhibit the distribution of electrical energy. So that maintenance must be done routinely and well. A critical component in a transformer that must always be maintained is the isolation of the transformer. Transformer insulation is a component that serves to prevent short circuits between coils on the inside of the transformer. So that maintenance and testing on transformer isolation must be done routinely to avoid damage to transformer isolation. Besides functioning as a deterrent to a short circuit, the transformer isolation also functions as a cooler on the transformer.

The transformer at the $150 \mathrm{kV}$ substation Bantul is an example of a transformer whose maintenance must be carried out routinely. Routine maintenance is usually done for two years. There are some isolation tests on transformers that become routine maintenance, namely the polarization index test, delta tangent, and Break Down Voltage (BDV). The polarization index test itself is a test carried out to determine the amount of leakage current (leakage current). While the delta tangent test is a dielectric loss test to determine the quality of winding insulation by measuring the capacitive leakage current, break Down Voltage or transformer oil breakdown voltage test is a test on the transformer that serves to determine to determine the condition of the transformer oil as insulation and to determine the limits of the transformer oil's ability to withstand electric conductivity. The following is the technical data of Transformer 1 on the $150 \mathrm{kV}$ substation Bantul which was carried out by testing the transformer insulation, as seen in Table 1.

TABLE I

TECHNicAl DATA For TRANSFORMER 1 AT THE 150 KV BANTUL SUBSTATION

\begin{tabular}{cll}
\hline \hline No. & \multicolumn{1}{c}{ Items } & \multicolumn{1}{c}{ Spesification } \\
\hline 1 & Serial Number & A45006 \\
2 & Special ID & TRAFO 1 \\
3 & Cicuit Designation & BAY TRAFO 1 \\
4 & Company & PLN P3B JB \\
5 & Location & Bantul \\
6 & Division & APP SALATIGA \\
7 & Year Manufactured & 1995 \\
8 & Manufactured Location & China \\
9 & Tank Type & Sealed-Conservator \\
10 & Class & ONAN/ONAF \\
11 & Coolant & OIL \\
12 & Weight & $102000 \mathrm{~kg}$ \\
13 & kV & $150 \mathrm{kV}$ \\
14 & VA Rating & 60 MVA \\
15 & Phases & 3 \\
16 & Winding Config $(H-L)$ & Wye-Wye \\
17 & Winding Config $(H-T)$ & Wye-Delta \\
18 & Winding Config $(L-T)$ & Wye-Delta \\
\hline \hline
\end{tabular}

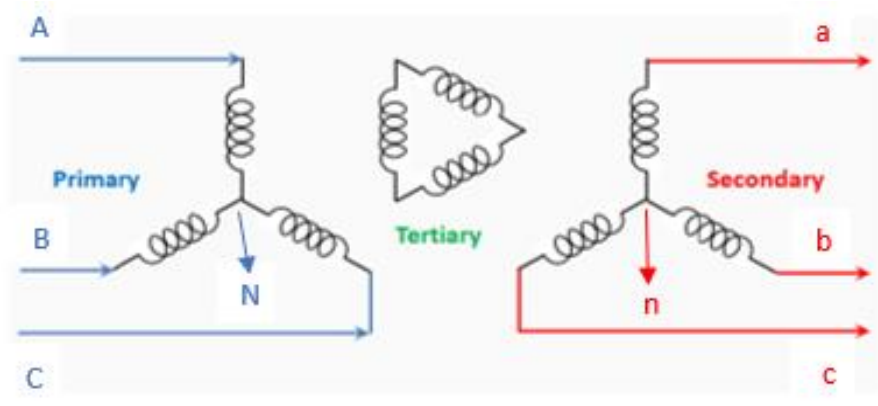

(a) 


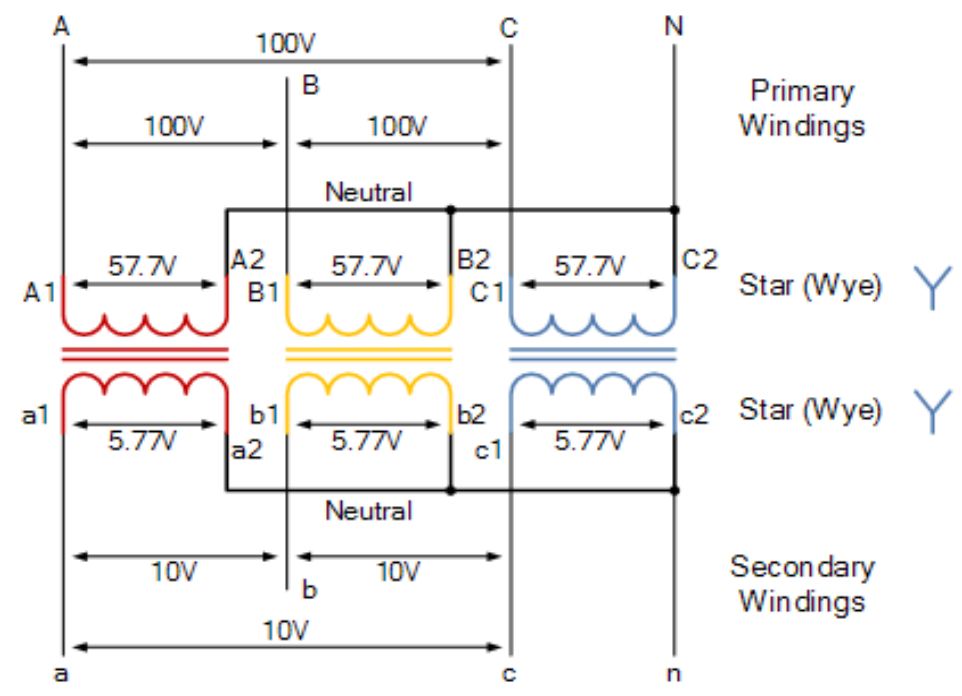

(b)

Fig. 5. Star-star winding connection in power transformer

\section{IV.2 Testing of Power Transformer}

Transformer testing is the final stage of a transformer production. The test aims to make the transformer production meets the specified standards before the transformer is operated. The test includes an insulation resistance test, induced potential test, and applied potential test. In the process of testing transformer isolation, there are several stages of implementation that must be carried out. This is done to reduce errors when testing and also to get maximum test results. There are three stages of implementation in the transformer testing process, namely, preparation, implementation, and completion.

Insulation resistance test aims to determine the amount of insulation resistance between the windings with the ground or between two windings. The test uses a megger (Mega ohm meter). The common method is to provide a dc voltage and represent the isolation conditions in Mega ohms. The measured insulation resistance is a function of leakage current that penetrates through insulation or through a leaky path on an external surface. This insulation resistance test can be affected by temperature, humidity, and leaking lines on external surfaces such as dirt on bushings or insulators. Megaohm meters usually have a testing capacity of $500,1000,2500$, or 5000 V DC. Figure 5 shows the star-star winding connection in power transformer.

The continuation of this insulation resistance test is testing the polarization index. The aim is to ensure that the equipment is suitable for operation or even for overvoltage tests. The polarization index is the ratio of insulation resistance at the tenth minute to the first minute with a constant voltage. Figure 6 shows the insulation test of power transformer using a megger.

The total current that appears when providing a steady-state dc voltage consists of:

a. Charging current due to the capacitance properties of the insulation measured. This current drops from the maximum value to zero very quickly.

b. Ion current due to molecular charge shifting in isolation. This transient current disappears to zero slower.

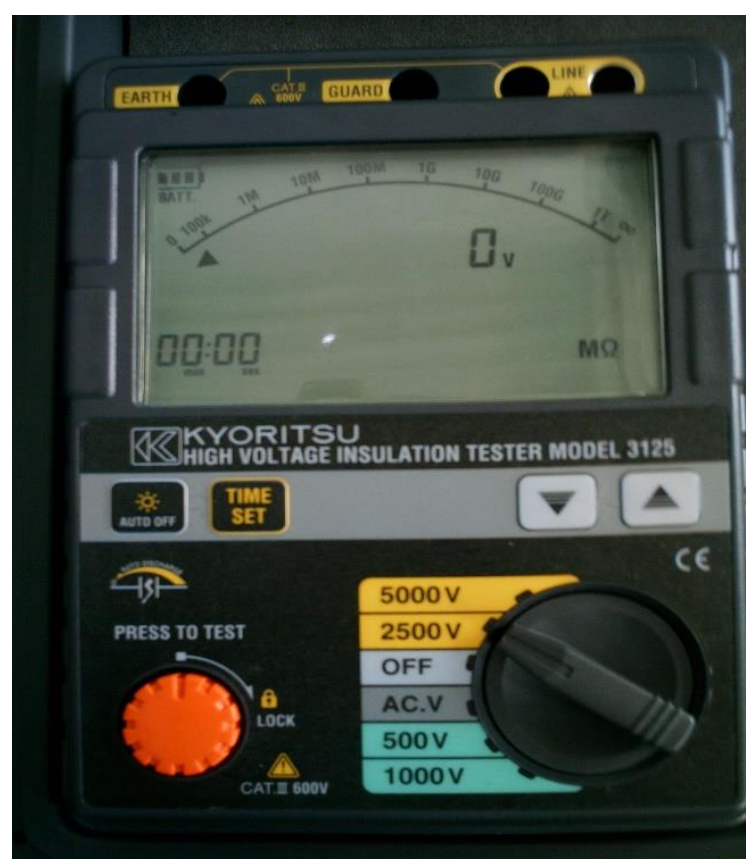

Fig. 6. Insulation test of power transformer using a high voltage insulation tester

Journal of Electrical Technology UMY, Vol. 3, No. 2 
TABLE II

SPECification of High Voltage Insulation Tester

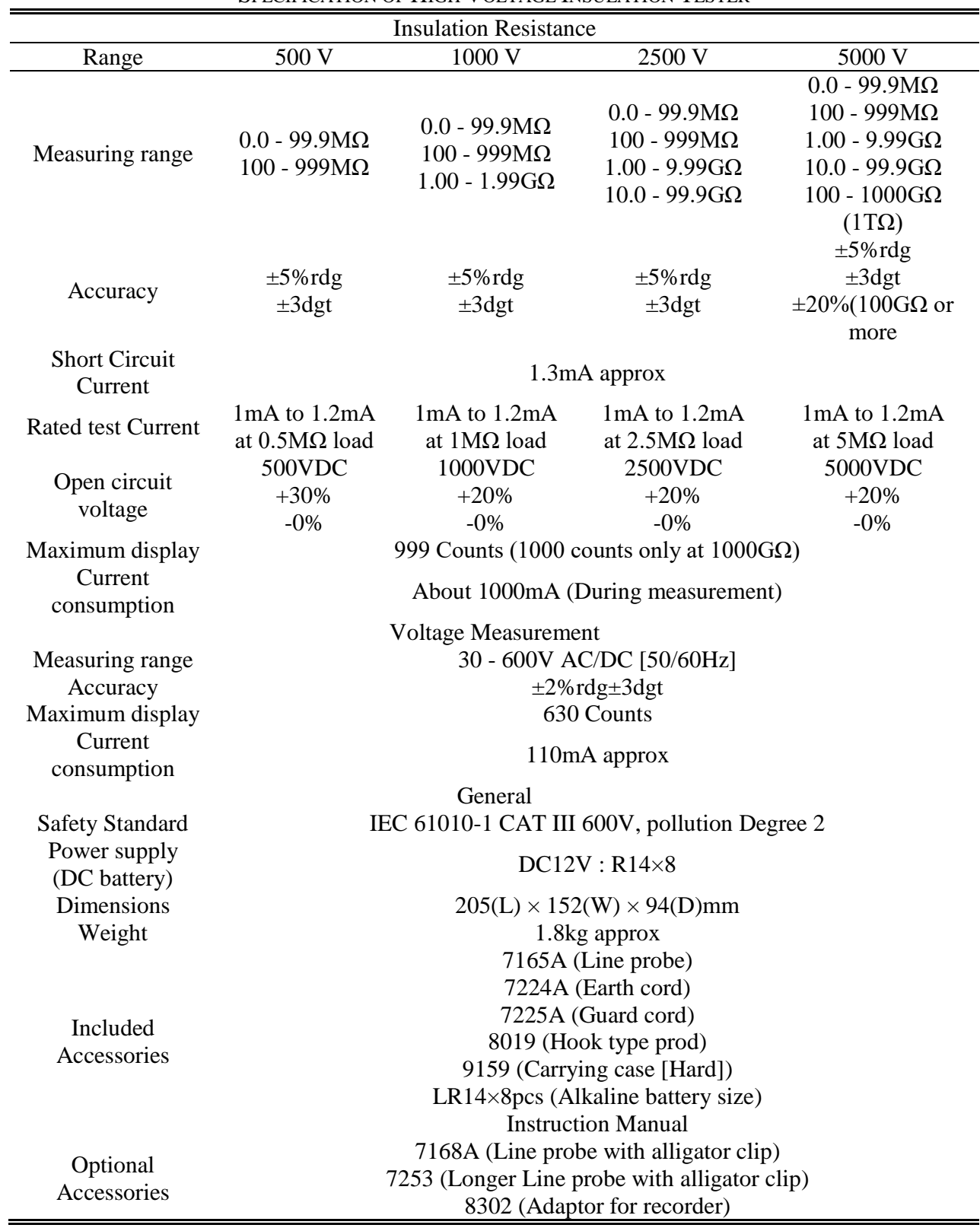

Leakage current is a real conduction current in insulation. Leakage current varies depending on the test voltage. It also includes leakage currents due to surface leakage due to contamination.

Leakage current increases faster in the presence of moisture than absorption current. Megaohm readings will not increase over time, just as the speed between poor insulation and fast insulation is good. This has an impact on the low polarization index. The advantage of the index ratio is the number of things that can affect megaohm readings such as temperature and humidity, both in one minute and ten minutes. The polarization index is a comparison between the value of insulation resistance in the tenth minute to the first minute. The categorization of isolation conditions based on the results of insulation resistance testing can be seen from the value of the insulation resistance itself and the polarization index.

\section{Conclusion}

In this study, all three tests were carried out on Transformer 1 in the $150 \mathrm{kV}$ Bantul substation. Polarization index testing itself is testing the leakage current on the transformer isolation by comparing the test results for 1 minute with the results of the 10-minute drive test. While delta 
tangent is testing capacitive leakage current in the isolation transformer, and break down voltage is a test of the ability of the breakdown voltage in transformer insulation oil. Based on the results of the analysis, it can be seen that the value of the transformer polarization index in 2016 and 2018, the average value between the windings has been in the rating of 1.25-2.0. As for the delta tangent test results in 2016 and 2018, the value between the capacitive parts is already in the rating of $0.18 \%$ $0.36 \%$. For the breakdown voltage test results in 2016 and 2018, the average breakdown voltage value is $43.9 \mathrm{kV} / \mathrm{mm}-65.5 \mathrm{kV} / \mathrm{mm}$. From these data, it can be concluded that the transformer isolation conditions in 2016 and 2018 are in good condition, although there was a decline in the transformer isolation conditions in 2016. However, the National Electric Company has made repairs and maintenance of the isolation transformer. This is seen due to an increase in the quality of transformer insulation in 2018. Repair and maintenance of transformer insulation are done to maximize the work system and the life of the transformer.

\section{References}

[1] R. M. A.A. Guzmán, "Transformer Maintenance Interval Management" in Schweitzer Engineering Laboratories Inc., Pullman, WA USA, 2005.

[2] T.A. Prevost, T.V. Oommen, "Cellulose insulation in oil-filled power transformers: Part I - history and development", Electrical Insulation Magazine IEEE, vol. 22, no. 1, pp. 28-35, 2006.

[3] "Through Fault Current In Power Transformer" in PT PLN PERSERO P3B Jawa Bali, Jakarta, 2014.

[4] S. R. a.S. Aminuddin, "Effect of Thermal Ageing on the Dielectric Properties and Dissolved Gas Analysis in Ester from Palm Oil and Kraft Composite Paper Insulation", The 3rd IEEE Conference on Power Engineering and Renewable Energy 2016, 2016.

[5] I.A.R. Gray, Transformer Chemistry Services A GUIDE TO TRANSFORMER OIL ANALYSIS.

[6] N. Frost, M. Chapman, R. Bruetsch, "Considerations for rotating low-voltage machine insulation designs", Conference Record of the 2008 IEEE International Symposium on Electrical Insulation, vol. 1 and 2, pp. 571-574, 2008.

[7] C.P. McShane, "Relative properties of the new combustion-resistant vegetable-oil-based dielectric coolants for distribution and power transformers", IEEE Transactions on Industry Applications, vol. 37, no. 4, pp. 1132-1139, 2001.

[8] G.K. Frimpong, T.V. Oommen, R. Asano, "A Survey of Aging Characteristics of Cellulose Insulation in Natural Ester and Mineral Oil", IEEE
Electrical Insulation Magazine, vol. 27, no. 5, pp. 36-48, 2011.

[9] K. Kanuga, "Degradation of polyester film exposed to accelerated indoor damp heat aging", Photovoltaic Specialists Conference (PVSC) 37th IEEE, 2011.

\section{Authors' information}

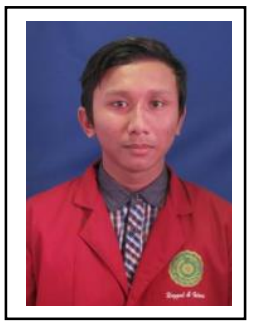

Arief Rahman Hidayat received B.Sc. degree from Department of Electrical Engineering, Universitas Muhammadiyah Muhammadiyah Yogyakarta, Yogyakarta, Indonesia.

His research interests are in operation of power system protection and power system planning.

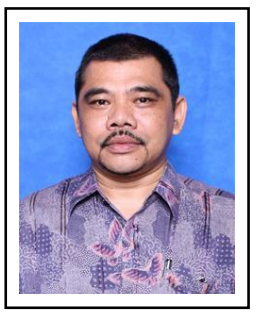

Agus Jamal obtained his B.Eng. in Electrical Engineering from Universitas Gadjah Mada, Indonesia, in 1994. His Master study was done at 2010 at the Electrical Engineering, Universitas Gadjah Mada, Indonesia. She currently is a lecture in department of Electrical Engineering, Universitas Muhammadiyah Yogyakarta. His main research interest is in power system operation, power quality, and building installation planning.

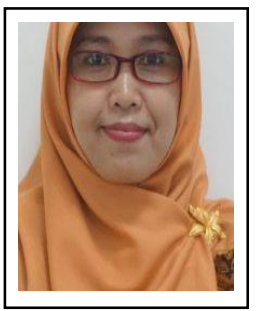

Anna Nur Nazilah Chamim obtained her B.Eng. in Electrical Engineering from Universitas Muhammadiyah Yogyakarta, Indonesia. Her Master study was done at 2015 at the Electrical Engineering, Universitas Gadjah Mada, Indonesia. She currently is a lecture in department of Electrical Engineering, Universitas Muhammadiyah Yogyakarta. Her main research interest is in electronics, telecommunication, and signal processing.

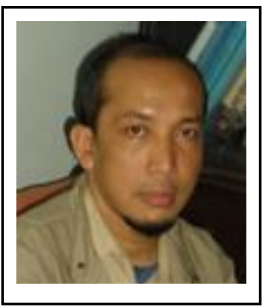

Ramadoni Syahputra received B.Sc. degree from Institut Teknologi Medan in 1998, M.Eng. degree from Department of Electrical Engineering, Universitas Gadjah Mada, Yogyakarta, Indonesia in 2002, and Ph.D degree at the Department of Electrical Engineering, Faculty of Industrial Technology, Institut Teknologi Sepuluh Nopember, Surabaya, Indonesia in 2015.

Dr. Ramadoni Syahputra is a Lecturer in Department of Electrical Engineering, Faculty of Engineering, Universitas Muhammadiyah Yogyakarta, Indonesia. His research interests are in computational of power system, artificial intelligence in power system, power system control, the application of fuzzy logic in power system, optimization, distributed energy resources, and renewable energy. 


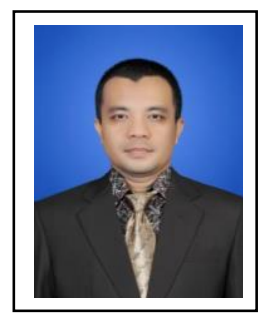

Jeckson obtained his B.Eng. in Electrical Engineering from Universitas Muhammadiyah Yogyakarta, Indonesia, in 1999. His Master study was done at 2015 at the Electrical Engineering, Universitas Negeri Padang, Indonesia. She currently is a lecture in department of Electrical engineering, Universitas Muhammadiyah Lampung. His main research interest is in powe sistem analysis, energy conversion, power electronics, and power system protection. 